\title{
Higher dietary folate intake reduces the breast cancer risk: a systematic review and meta-analysis
}

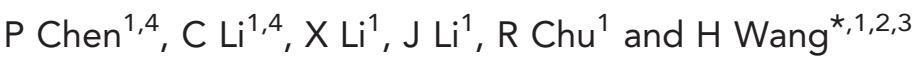

${ }^{1}$ Key Laboratory of Food Safety Research, Institute for Nutritional Sciences, Shanghai Institutes for Biological Sciences, Chinese Academy of Sciences, University of the Chinese Academy of Sciences, Shanghai 200031, People's Republic of China; ${ }^{2}$ Key Laboratory of Food Safety Risk Assessment, Ministry of Health, Beijing 100021, People's Republic of China and ${ }^{3}$ School of Life Science and Technology, ShanghaiTech University, Shanghai 200031, People's Republic of China

Background: Many epidemiological studies have investigated the association between folate intake, circulating folate level and risk of breast cancer; however, the findings were inconsistent between the studies.

Methods: We searched the PubMed and MEDLINE databases updated to January, 2014 and performed the systematic review and meta-analysis of the published epidemiological studies to assess the associations between folate intake level, circulating folate level and the overall risk of breast cancer.

Results: In all, 16 eligible prospective studies with a total of 744068 participants and 26205 breast cancer patients and 26 case-control studies with a total of 16826 cases and 21820 controls that have evaluated the association between folate intake and breast cancer risk were identified. Pooled analysis of the prospective studies and case-control studies suggested a potential nonlinearity relationship for dietary folate intake and breast cancer risk. Prospective studies indicated a U-shaped relationship for the dietary folate intake and breast cancer risk. Women with daily dietary folate intake between 153 and $400 \mu \mathrm{g}$ showed a significant reduced breast cancer risk compared with those $<153 \mu \mathrm{g}$, but not for those $>400 \mu \mathrm{g}$. The case-control studies also suggested a significantly negative correlation between the dietary folate intake level and the breast cancer risk. Increased dietary folate intake reduced breast cancer risk for women with higher alcohol intake level, but not for those with lower alcohol intake. No significant association between circulating folate level and breast cancer risk was found when the results of 8 identified studies with 5924 participants were pooled.

Conclusions: Our studies suggested that folate may have preventive effects against breast cancer risk, especially for those with higher alcohol consumption level; however, the dose and timing are critical and more studies are warranted to further elucidate the questions.

Breast cancer is the most commonly diagnosed malignancy and the leading cause of cancer-related deaths of women worldwide. The recognised factors associated with the increased risks of breast cancer include genetic mutations (breast cancer 1, early onset (BRCA1), breast cancer 2, early onset (BRCA2), TP53 and partner and localizer of BRCA2 (PALB2) and so on), obesity, menstrual history and status, reproductive history and lifestyle (Hankinson et al, 2004). Nutritional status and dietary factors may also contribute to breast cancer development. It was estimated that approximately one-third of all cancer deaths could have been prevented by appropriate dietary modification (Khan et al, 2008). Previous studies have suggest that increased consumption of total

\footnotetext{
*Correspondence: Professor H Wang; E-mail: huiwang@sibs.ac.cn

${ }^{4}$ These authors contributed equally to this work.
}

Received 5 December 2013; revised 27 February 2014; accepted 28 February 2014; published online 25 March 2014 
dietary fibre, total dairy intake, vitamin $\mathrm{D}$, vitamin $\mathrm{A}$ or soy isoflavone consumption may reduce breast cancer risk (Franceschi, 1997; Chen et al, 2010; Dong and Qin, 2011). These results highlight potential benefits for breast cancer prevention through dietary modification.

Folate plays important roles in DNA synthesis and DNA methylation that are essential for DNA integrity maintenance and gene expression regulation. Folate deficiency may lead to $S$-adenosylmethionine depletion, DNA methylation alteration and disruption of genome integrity and DNA repair process that may collectively alter the expression of critical tumour suppressor genes and oncogenes (Choi and Mason, 2000). During the past several decades, many epidemiological studies have been conducted to evaluate the relationship between folate intake or blood folate levels and the risk of breast cancer. Several studies have suggested that high folate intake or high blood folate level may reduce the risk of breast cancer, especially for those with high alcohol consumption (Rohan et al, 2000; Beilby et al, 2004); however, other studies found no such associations (Wu et al, 1999; Larsson et al, 2008). Considering the inconsistent results generated from various epidemiological studies, we conducted the meta-analysis studies with larger sample size compared with two previous meta-analysis studies (Lewis et al, 2006; Larsson et al, 2007), which assumed a linear relationship between the folate intake level and the breast cancer risk, to examine currently available epidemiological data and determine whether any associations exist between folate intake, circulating folate level and breast cancer susceptibility. In addition, the dose effect of folate intake and breast cancer risk was also evaluated based on the published epidemiological studies. We also further tested whether the association between folate intake and breast cancer risk could be modified by alcohol consumption that negatively regulates folate absorption and metabolism.

\section{MATERIALS AND METHODS}

Study selection. We searched the MEDLINE and PubMed databases for relevant studies published updated to January, 2014. To minimise the restrictions, the terms breast cancer in combination with folate or folic acid were used in the literature search. The references of the retrieved publications were checked to identify any missing studies. Only studies reported in English were included. The study was conducted following the MOOSE statement and the PRISMA guidelines.

Two authors (PC and CL) independently reviewed the retrieved abstracts or manuscripts to determine the eligibility of the studies for inclusion in our meta-analysis. Published studies were selected based on the following criteria: (1) a prospective, case-control or cross-sectional study design; (2) reported an association between folate intake or circulating folate levels in categories and breast cancer risk; (3) provided the relative risk (RR) or odds ratio (OR) estimates and their 95\% confidence intervals (95\% CIs) or sufficient data to calculate the estimates for the higher category exposure level compared with the lowest category level. As a result, we identified 49 eligible studies from a total of 1051 published studies. The working flowchart for selecting the eligible studies is briefly explained in Figure 1.

Data extraction. The following data were extracted from each identified study: the first author's last name, publication year, study type and study period, location or ethnicity of participants in the studies, sample size, menopausal status, categories of folate intake or serum folate levels, and risk estimates (RRs or ORs) with its $95 \%$ confidence intervals for highest category $v s$ the lowest category and the adjusted covariates in the statistical analysis. If available, we extracted the estimates that reflected the greatest degree of adjustment for potential confounders; otherwise, we calculated the estimates and their 95\% CIs based on the available data.

Quality appraisal of the studies. The quality of the selected studies was independently assessed by two authors (PC and CL), and the discrepancies were resolved by discussion with the third author (HW). The appraisal followed the guidelines of the modified Newcastle-Ottawa Quality Assessment Scale (NOS) documents. For case-control or cohort studies, a total of nine points were designated according to the basic characteristics of the studies including: (1) selection, total score: 4; (2) comparability, total score: 2; and (3) exposure (case-control)/outcome (cohort), total score: 3. The quality for the cohort studies and the casecontrol studies were assessed independently. For cohort studies, four points were awarded if the cohort was performed in the fixed community and all the cases were identified in the following-up time of the cohort, no breast cancer was identified when the participants were recruited and the dietary and total folate intake level was derived from the structured interview in the selection category. In the comparability category, two points were awarded if the study controlled for age, body mass index, age at first birth, age at menarche, age at menopause, menopausal status, use of oral contraceptives, use of postmenopausal hormones, family history of breast cancer, history of benign breast disease and the alcohol intake. For the outcome category, three points were awarded if the breast cancer patients were identified with the medical records or the national disease agencies, with median or mean follow-up time of $>10$ years and $>90 \%$ follow-up rate. For the nested casecontrol studies and the case-control studies, four points were awarded for the selection category if the cases were confirmed with hospital/medical records in specific medical centres, the controls were selected with no history of the breast cancer and from the same community of the cases. For comparability category, two points were awarded if the study controlled for covariants as listed above for the cohort studies. In the outcome category, three points were awarded if the assessment of exposure was based on structured interview or secure lab test and the same method was applied to the cases and controls in addition to the similar response rate for the cases and controls.

Statistical analysis. We used the inverse variance weighting method to calculate the summary estimate and related 95\% CI. The RRs and ORs with their 95\% CIs for the highest category in comparison with the lowest category for each study were extracted or calculated, and the ORs from nested case-control studies were assumed as the estimates of the RRs for prospective studies. The squared inverse variance for the logarithm RR/OR was considered as the appropriate weight for each study. We used the standard fixed-effect model as well as the DerSimonian and Laird randomeffects model that considers both within- and between-study variations. When the risk estimates were provided in a stratified way (such as by menopausal status, oestrogen status, alcohol use) in the original report, we calculated the pooled estimate for each study before the final meta-analysis unless the stratification analysis was conducted. For studies having overlapping participants, the most completed one or the one with largest sample size was used to evaluate the overall association between dietary or total folate intake level and the breast cancer risk; however, the one with the most detailed information related to the stratification factors was included in the stratification studies to assess the association between folate intake level and breast cancer sufficiently.

In the dose-response meta-analysis of folate intake and breast cancer risk, we first used the methods reported by Greenland and Longnecker (1992) and Orsini et al (2006) to compute the studyspecific dose-response effects from the correlated log RR or log OR estimates across the categories for folate intake. For any report that did not provide the distribution of case patients and control subjects by exposure category, we estimated the slopes with the 


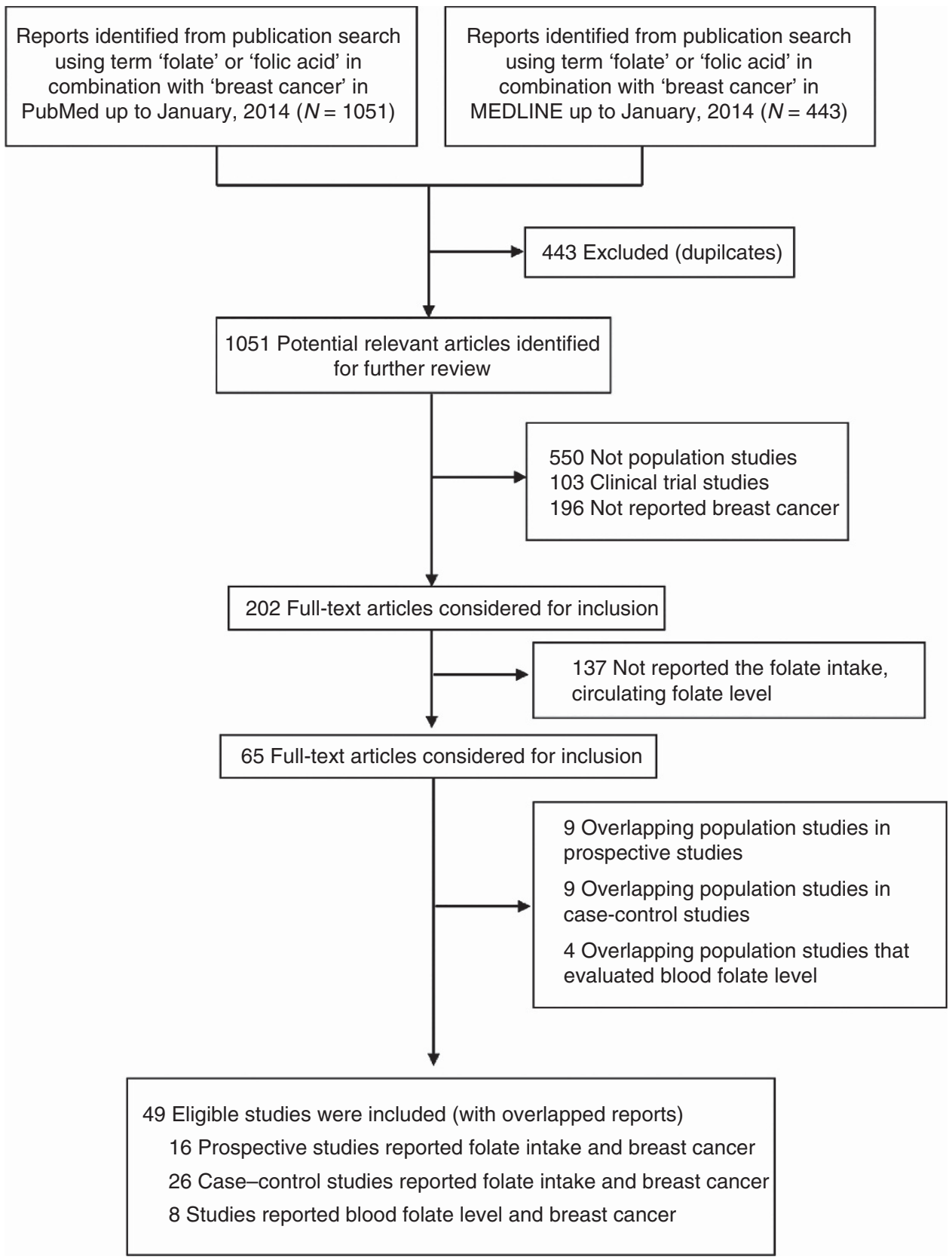

Figure 1. Working flowchart for study selection and data acquisition.

variance-weighted least squares regression model as suggested by Larsson et al (2007). Then, the individual estimates were pooled with the inverse variance weighting method to calculate the overall estimates for folate intake (per $100 \mu \mathrm{g}$ per day increment) and breast cancer risk. To estimate the dose-response trend for log RRs or log ORs across exposure categories, we applied the generalised least squares regression model (Greenland and Longnecker, 1992) to pool the prospective studies and the case-control studies that have reported dose-specific RRs/ORs for dietary or total folate intake and breast cancer risk, respectively. We examined the potential nonlinear dose-response relationship between folate intake levels and breast cancer risk by modelling folate intake levels using restricted cubic splines with three knots at 10\%, 50\% and $90 \%$ percentiles of the folate intake distribution. To reduce potential statistical bias, at least four eligibility individual studies were pooled with the generalised least squares regression model in the stratification studies. The $P$-value for nonlinearity test was determined by testing the null hypothesis that the coefficient of the second spline is equal to 0 .

The Cochrane Q-test and $I^{2}$ statistics were used to evaluate the statistical heterogeneity among studies under the assumption of random-effects model. A $P$-value of $<0.05$ for $Q$-test or $I^{2}>25 \%$ was considered statistically significant heterogeneity among the studies. If significant heterogeneity was detected, the results for the random-effects model were used as a more appropriate model for interpretation compared with the fixed-effects model. To identify any potential publication bias, the funnel plots and Egger's linear regression test were executed, and significant publication bias was considered when the $P$-value was $<0.05$. When significant publication bias for folate intake or circulating folate level and breast cancer risk was identified, the trim and fill method was used to adjust the publication bias (Duval and Tweedie, 2000). All statistical analyses were conducted with $\mathrm{R}$ software (version 2.14.2) and the Meta package for $\mathrm{R}$ (www.r-project.org), the Stata 
statistical software (version 12.0, StataCorp, College Station, TX, USA) and the Review Manager (version 5.2.4, The Nordic Cochrane Centre, Copenhagen, Denmark).

\section{RESULTS}

Study characteristics for folate intake and breast cancer risk. Based on our literature search, we identified 21 prospective cohort studies (Zhang et al, 1999; Rohan et al, 2000; Sellers et al, 2001, 2002; Cho et al, 2003; Feigelson et al, 2003; Sellers et al, 2004; Baglietto et al, 2005; Zhang et al, 2005; Stolzenberg-Solomon et al, 2006; Lajous et al, 2006b; Cho et al, 2007; Ericson et al, 2007; Kabat et al, 2008; Larsson et al, 2008; Duffy et al, 2009; Maruti et al, 2009b; Roswall et al, 2010; Stevens et al, 2010; Shrubsole et al, 2011; Bassett et al, 2013), 4 prospective nested case-control studies (Le Marchand et al, 2004; Tjonneland et al, 2006; Lin et al, 2008; Maruti et al, 2009a) and 29 case-control studies (Graham et al, 1991; Freudenheim et al, 1996; Thorand et al, 1998; Potischman et al, 1999; Ronco et al, 1999; Negri et al, 2000; Levi et al, 2001; Shrubsole et al, 2001; Sharp et al, 2002; Adzersen et al, 2003; Zhu et al, 2003; Shrubsole et al, 2004; Chen et al, 2005; Lajous et al, 2006a; Chou et al, 2007; Suzuki et al, 2008; Gao et al, 2009; Ma et al, 2009a, b; Beasley et al, 2010; Lee et al, 2010; Yang et al, 2010; Marian et al, 2011; Zhang et al, 2011; Lee et al, 2012; Tavani et al, 2012; Islam et al, 2013; Yang et al, 2013; Gong et al, 2014) that evaluated folate intake level and breast cancer risk (Figure 1). Detailed characteristics of the studies are provided in the Supplementary Tables 1-3. Among the 25 prospective studies (including cohort studies and nested case-control studies), 9 studies (Zhang et al, 1999; Rohan et al, 2000; Sellers et al, 2002; Cho et al, 2003; Feigelson et al, 2003; Sellers et al, 2004; Baglietto et al, 2005; Maruti et al, 2009a; Roswall et al, 2010) were conducted in the same populations as the other 8 studies (Sellers et al, 2001; Zhang et al, 2005; Tjonneland et al, 2006; Cho et al, 2007; Kabat et al, 2008; Maruti et al, 2009b; Stevens et al, 2010; Bassett et al, 2013). Thus, only the most completed or detailed results of the studies were included in the following meta-analysis or stratification studies. Among the 16 included individual prospective studies, including 14 cohort studies (Zhang et al, 1999; Sellers et al, 2001; Zhang et al, 2005; Stolzenberg-Solomon et al, 2006; Lajous et al, 2006b; Cho et al, 2007; Ericson et al, 2007; Kabat et al, 2008; Larsson et al, 2008; Maruti et al, 2009b; Roswall et al, 2010; Stevens et al, 2010; Shrubsole et al, 2011; Bassett et al, 2013) and 2 nested case-control studies (Le Marchand et al, 2004; Lin et al, 2008),
10 were conducted in North America, 4 in Europe, 1 in Australia and 1 in China. Overall, the 14 individual prospective cohort studies included a total of 738769 participants with 24168 breast cancer cases with the median follow-up of 12 years (range from 6 to 20 years; Supplementary Table 1). Of the two included prospective nested case-control studies, a total of 2037 breast cancer patients and 3262 controls were included (Supplementary Table 1). The NOS quality points of the prospective studies are provided in the Supplementary Table 4. For prospective cohort studies, 10 were categorised as higher quality (NOS point $>5$ ) and 4 were lower quality (NOS point $\leqslant 5$ ). The two nested case-control studies were categorised as higher quality.

Among the identified 29 case-control studies that evaluated the association between breast cancer risk and folate intake (Supplementary Table 2), we excluded three studies conducted by Shrubsole et al (2004), Islam et al (2013) and Negri et al (2000) from the meta-analysis because of the overlapping participants with studies conducted by Shrubsole et al (2001), Suzuki et al (2008) and Tavani et al (2012), respectively. Thus, 12 populationbased case-control studies and 14 hospital-based case-control studies were included. The 26 studies had recruited a total of 16826 cases and 21820 controls, and 10 studies were conducted in North America, 9 in Asia, 6 in Europe, and 1 in Brazil. Of them, 25 studies and 3 studies evaluated the dietary and total folate intake level and breast cancer risk, respectively. The NOS quality points of the studies are provided in Supplementary Table 5. Of these, 18 were categorised as higher quality (NOS point $>6$ ) and 8 were assigned as lower quality (NOS point $\leqslant 6$ ).

Folate intake and breast cancer risk. From the meta-analysis of the prospective studies, no significant association between dietary folate intake and breast cancer risk was found (pooled $\mathrm{RR}=0.95$; $95 \% \mathrm{CI}=0.87-1.03$; Figure 2 ) for those in the highest category of dietary intake compared with those in the lowest category (Table 1). However, Egger's test suggested that significant publication bias existed $(P=0.023)$. When we applied the trim and fill methods to adjust for the publication bias, we still found no significant reduced breast cancer risk for those with highest category dietary folate intake (pooled $\mathrm{RR}=1.04 ; 95 \% \mathrm{CI}=$ $0.94-1.15)$. The higher total folate intake also showed no reduction of breast cancer risk (pooled $\mathrm{RR}=0.97 ; 95 \% \mathrm{CI}=0.87-1.08$; Figure 3) under the random-effects model. Participants who took folate supplements had no reduced breast cancer risk compared with those who did not (pooled $\mathrm{RR}=1.07 ; 95 \% \mathrm{CI}=0.95-1.21$; Table 1). In the stratification analysis of folate intake and breast

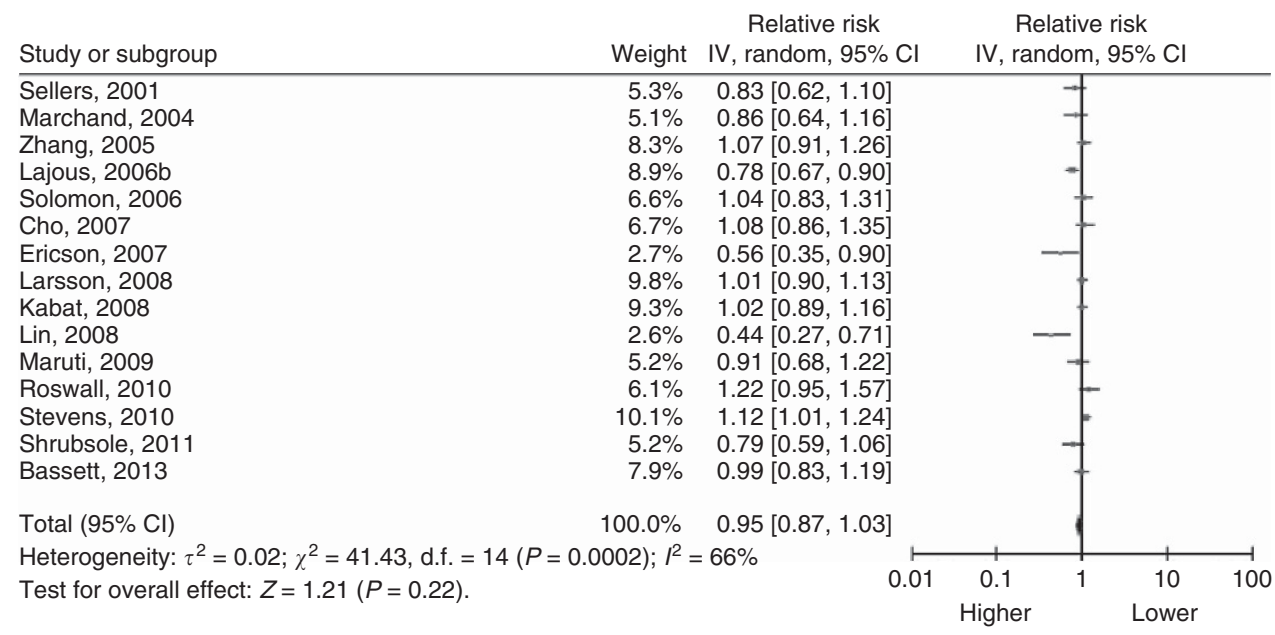

Figure 2. The pooled RR of breast cancer for women in the highest category of daily dietary folate intake level compared with those in the lowest category for the prospective studies. 
Table 1. Summary RR for the association between folate intake level and breast cancer risk of the prospective studies (highest vs lowest category)





Figure 3. The pooled RR of breast cancer for women in the highest category of daily total folate intake level compared with those in the lowest category for the prospective studies.

cancer risk by the quality of the studies, menopausal status of the women, the ethnicity of the participants, oestrogen receptor (ER) status for the breast cancer patients and whether the estimate was adjusted for the alcohol intake in the individual studies, we found no statistically significant heterogeneity for the summary estimate between the stratifications (Table 1).

For the 25 case-control studies, the pooled OR was $0.79(95 \%$ $\mathrm{CI}=0.67-0.92$; Table 2) for participants with highest category of 
Table 2. Summary OR for the association between folate intake and breast cancer risk of the case-control studies (highest vs lowest category)

\begin{tabular}{|c|c|c|c|c|c|c|c|}
\hline Stratification group & No. of study & $\begin{array}{l}\text { Fixed-effect model, OR } \\
(95 \% \mathrm{Cl})\end{array}$ & $\begin{array}{c}\text { Random-effects model, } \\
\text { RR }(95 \% \mathrm{Cl})\end{array}$ & Q/d.f. & $1^{2}$ & $P$ & $\begin{array}{c}\text { Egger's } \\
\text { test }\end{array}$ \\
\hline \multicolumn{8}{|l|}{ Intake means } \\
\hline $\begin{array}{l}\text { Total } \\
\text { Dietary }\end{array}$ & $\begin{array}{r}3 \\
25\end{array}$ & $\begin{array}{l}0.93(0.77-1.11) \\
0.89(0.84-0.96)\end{array}$ & $\begin{array}{l}0.87(0.61-1.23) \\
0.79(0.67-0.92)\end{array}$ & \begin{tabular}{|c|}
$6.14 / 2$ \\
$135.78 / 24$ \\
\end{tabular} & $\begin{array}{l}67.4 \% \\
82.3 \% \\
\end{array}$ & $\begin{array}{r}0.047 \\
<0.001 \\
\end{array}$ & $\begin{array}{l}0.414 \\
0.006\end{array}$ \\
\hline \multicolumn{8}{|l|}{ Menopause status } \\
\hline $\begin{array}{l}\text { Premenopause (DF) } \\
\text { Postmenopause (DF) }\end{array}$ & $\begin{array}{l}8 \\
9\end{array}$ & $\begin{array}{l}0.83(0.71-0.97) \\
0.85(0.76-0.95)\end{array}$ & $\begin{array}{l}0.78(0.53-1.14) \\
0.73(0.59-0.92)\end{array}$ & $\begin{array}{l}34.66 / 7 \\
23.68 / 8\end{array}$ & $\begin{array}{l}79.8 \% \\
66.2 \%\end{array}$ & $\begin{array}{r}<0.001 \\
0.003\end{array}$ & $\begin{array}{l}0.550 \\
0.014\end{array}$ \\
\hline \multicolumn{8}{|l|}{ Ethnicity } \\
\hline $\begin{array}{l}\text { North American (DF) } \\
\text { Others (DF) }\end{array}$ & $\begin{array}{r}8 \\
17 \\
\end{array}$ & $\begin{array}{l}1.01(0.92-1.11) \\
0.81(0.74-0.88)\end{array}$ & $\begin{array}{l}0.91(0.76-1.09) \\
0.73(0.58-0.93)\end{array}$ & \begin{tabular}{|c|}
$22.2 / 7$ \\
$101.75 / 16$ \\
\end{tabular} & $\begin{array}{c}68.5 \% \\
84 \%\end{array}$ & $\begin{array}{l}<0.001 \\
<0.001\end{array}$ & $\begin{array}{r}<0.001 \\
0.223\end{array}$ \\
\hline \multicolumn{8}{|l|}{ Study type } \\
\hline $\begin{array}{l}\text { Population (DF) } \\
\text { Hospital (DF) }\end{array}$ & $\begin{array}{l}13 \\
12 \\
\end{array}$ & $\begin{array}{l}0.99(0.92-1.07) \\
0.70(0.63-0.79)\end{array}$ & $\begin{array}{l}0.86(0.71-1.05) \\
0.67(0.54-0.85)\end{array}$ & $\begin{array}{c}73.9 / 12 \\
37.03 / 11\end{array}$ & $\begin{array}{c}83.8 \% \\
70 \%\end{array}$ & $\begin{array}{l}<0.001 \\
<0.001\end{array}$ & $\begin{array}{l}0.008 \\
0.529\end{array}$ \\
\hline \multicolumn{8}{|l|}{ Alcohol adjustment } \\
\hline $\begin{array}{l}\text { Alcohol unadjusted (DF) } \\
\text { Alcohol adjusted (DF) }\end{array}$ & $\begin{array}{r}17 \\
8\end{array}$ & $\begin{array}{l}0.88(0.81-0.94) \\
0.93(0.83-1.04)\end{array}$ & $\begin{array}{l}0.74(0.60-0.92) \\
0.84(0.66-1.06)\end{array}$ & \begin{tabular}{|c|}
$109.57 / 16$ \\
$25.25 / 7$
\end{tabular} & $\begin{array}{l}85.4 \% \\
72.3 \% \\
\end{array}$ & $\begin{array}{l}<0.001 \\
<0.001\end{array}$ & $\begin{array}{l}0.024 \\
0.048\end{array}$ \\
\hline \multicolumn{8}{|l|}{ Study quality } \\
\hline $\begin{array}{l}\text { Higher (DF) } \\
\text { Lower (DF) }\end{array}$ & $\begin{array}{r}17 \\
8\end{array}$ & $\begin{array}{l}0.90(0.84-0.98) \\
0.88(0.79-0.99)\end{array}$ & $\begin{array}{l}0.76(0.61-0.94) \\
0.86(0.70-1.05)\end{array}$ & \begin{tabular}{|c|}
$117.28 / 16$ \\
$18.36 / 7$
\end{tabular} & $\begin{array}{l}86.4 \% \\
61.9 \% \\
\end{array}$ & $\begin{array}{r}<0.001 \\
0.010 \\
\end{array}$ & $\begin{array}{l}0.004 \\
0.497\end{array}$ \\
\hline
\end{tabular}

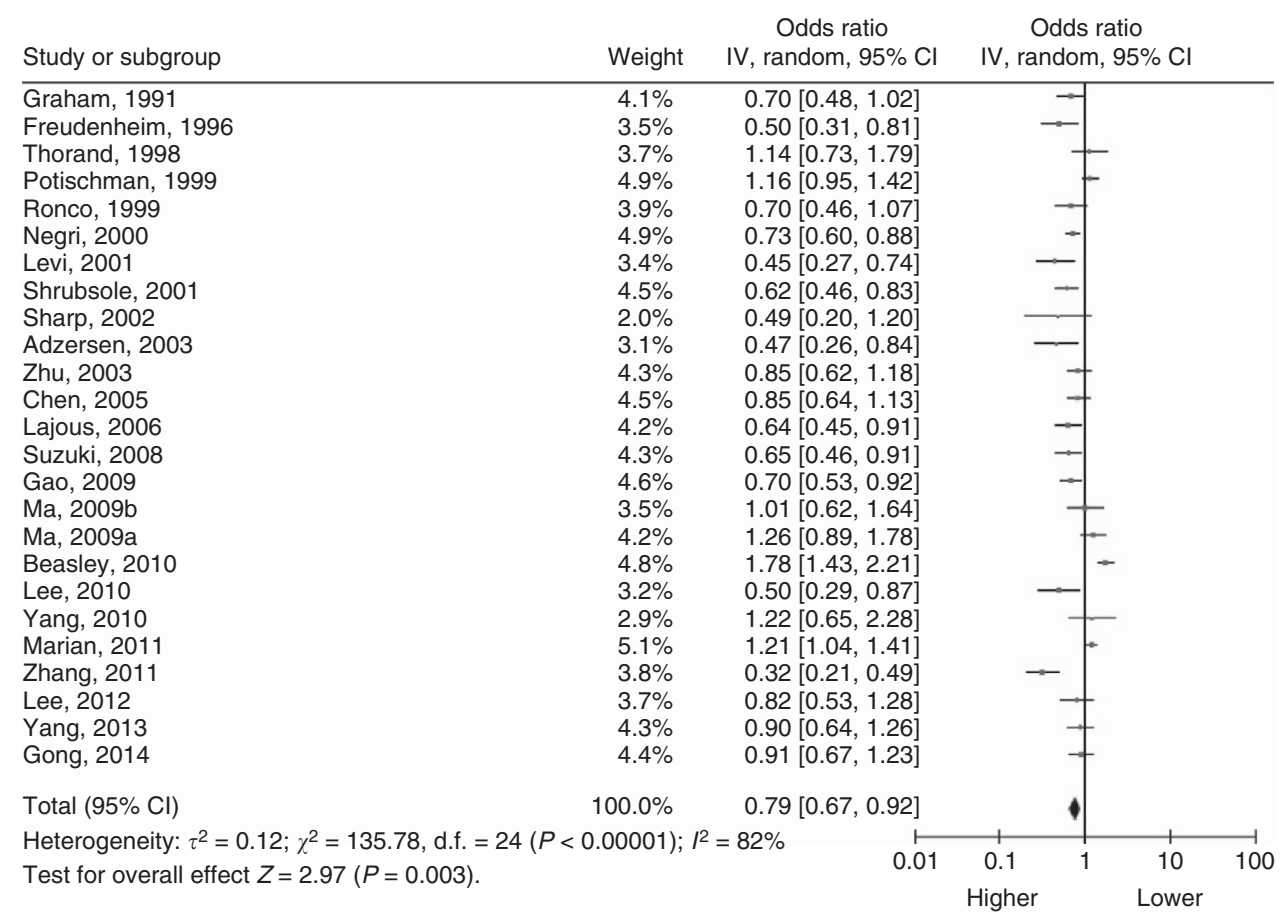

Figure 4. Forest plot of the summary OR of breast cancer for women in the highest category of dietary folate intake compared with those in the lowest category for the case-control studies.

dietary folate intake compared with those of lowest category, suggesting that higher dietary folate intake may reduce breast cancer risk (Figure 4). However, Egger's test suggested that significant publication bias may exist for the studies $(P=0.006)$.
When the trim and fill method was applied for the publication bias adjustment, we found no significant association between dietary folate intake and breast cancer risk, with the pooled OR of 0.99 $(95 \% \mathrm{CI}=0.84-1.16)$ under the random-effects model $\left(I^{2}=86.1 \%\right.$, 
Supplementary Figure 1). There was also no significant reduction of breast cancer risk for highest category of total folate intake compared with those of lowest category (pooled OR $=0.87 ; 95 \%$ $\mathrm{CI}=0.61-1.23$; Table 2). No significant publication bias was found for the meta-analysis study of total folate intake and breast cancer risk. In the stratification studies of dietary folate intake and breast cancer risk, we found that higher dietary folate may reduce the breast cancer risk in the populations of Europe, Australia or Asia (pooled $\mathrm{OR}=0.73 ; 95 \% \mathrm{CI}=0.58-0.93$ ) but not in the United States (pooled $\mathrm{OR}=0.91 ; 95 \% \mathrm{CI}=0.76-1.09$ ). The pooled estimate from the hospital-based case-control studies suggested that subjects in the highest category of dietary folate intake showed a $33 \%$ decrease in breast cancer risk (pooled OR $=0.67 ; 95 \%$ $\mathrm{CI}=0.54-0.85$; Table 2), whereas the population-based studies did not find such an association (Table 2). After stratifying the estimate of the dietary folate intake according to the adjustment of alcohol intake, we found that the pooled OR was 0.74 (95\% CI $=0.60-0.92$; trim and fill-adjusted pooled $\mathrm{OR}=0.97,95 \% \mathrm{CI}=0.79-1.17$ ) for those studies without alcohol adjustment. The pooled OR was 0.84 (95\% CI $=0.66-1.06)$ for those studies with alcohol intake adjustment (Table 2). Pooled estimate for the studies with higher-quality studies suggested that higher folate intake may reduce the breast cancer risk, but not for the studies with lower quality (Table 2).

As there were significant variations for the categories of folate intake between the studies under the assumption of a linear doseeffect relationship between folate intake and breast cancer risk as indicated by the two previous meta-analysis studies (Lewis et al, 2006; Larsson et al, 2007), we first normalised the association between folate intake and breast cancer risk for an increment of $100 \mu \mathrm{g}$ per day for each study. We found that an increment of $100 \mu \mathrm{g}$ per day intake was not in significant association with breast cancer risk for dietary folate (pooled $\mathrm{RR}=1.00$; $95 \% \mathrm{CI}=0.98$ 1.01 ) or total folate (pooled $R R=1.00 ; 95 \% \mathrm{CI}=0.995-1.013$ ) for the prospective studies under the assumption of a linear dose-effect relationship between folate intake and breast cancer risk. No publication bias was found for the meta-analyses (Egger's test, $P=0.228$ and 0.377 , respectively). However, when we evaluated the dose-effect relationship for dietary folate and the breast cancer risk with the generalised least squares regression model, a statistically marginal significant departure from linearity $(P$ for linearity $=0.080$, Figure 5 ) was found for the prospective studies. We noticed a U-shaped dose-effect relationship for the daily folate

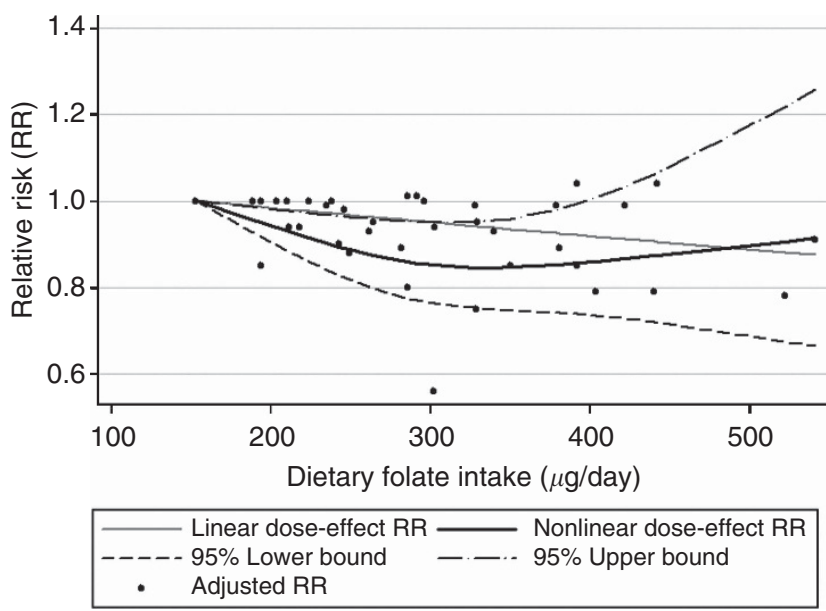

Figure 5. Dose-response relationship for dietary folate intake level and the RR of breast cancer for the prospective studies. The median value of the lowest category interval (153 $\mu \mathrm{g}$ per day) was used as referent baseline level $(P$ for linearity $=0.080)$. intake level and the breast cancer risk. There was a significant decreased risk for breast cancer risk for participants with the daily dietary folate intake between $153 \mu \mathrm{g}$ and $400 \mu \mathrm{g}$ compared with those of $<153 \mu \mathrm{g}$ (Figure 5). Women with dietary folate intake of $>400 \mu \mathrm{g}$ showed a reduced but not statistically significant breast cancer risk compared with those of $<153 \mu \mathrm{g}$. In contrast, a linear dose-effect relationship for the total folate intake and breast cancer risk was found $(P=0.781$, Supplementary Figure 2$)$ for the prospective studies without any evidence for the preventive effects of total folate intake against breast cancer risk. We also evaluated the dose-effect relationship between dietary/total folate intake level and breast cancer risk for prospective studies with the stratification of study quality (higher/lower), study region (USA/other countries) and menopausal status (pre-/post-menopausal). The results for the stratification studies are provided in Supplementary Figure 3.

For case-control studies, we found that a $100 \mu \mathrm{g}$ per day increment of dietary folate intake led to a $5 \%$ decrease of breast cancer risk (pooled $\mathrm{OR}=0.95,95 \% \mathrm{CI}=0.92-0.98$ ) under random-effects model when the study-specific estimate was pooled, and marginal publication bias was found (Egger's test, $P=0.045$ ). When we applied the trim and fill methods to adjust the potential publication bias, we found statistically marginal reduced breast cancer risk for the $100 \mu \mathrm{g}$ per day increased dietary folate intake (pooled $\mathrm{OR}=0.97,95 \% \mathrm{CI}=0.94-1.01$ ). When we performed the generalised least squares regression model to evaluate the dose-effect relationship for the dietary folate intake and breast cancer risk for the case-control studies, a statistically marginal significant departure from the linearity model was found $(P=0.069$, Figure 6). A significantly reduced breast cancer risk was noticed under the assumption of the linearity and the nonlinearity models for women with higher dietary folate intake compared with those with dietary intake $<130.5 \mu \mathrm{g}$ per day. A $100 \mu \mathrm{g}$ per day increase of dietary folate leads to an $\sim 9 \%$ reduction in breast cancer risk $(\mathrm{OR}=0.91 ; 95 \% \mathrm{CI}=0.86-0.97)$. The associations between the dietary folate intake level and breast cancer risk in the stratification of quality of the studies (higher/lower quality), menopausal status (pre-/post-menopausal), study region (USA/ other countries) and hormone receptor status (ER positive/ negative) are provided in the Supplementary Figure 4.

Interaction of alcohol consumption with folate and breast cancer risk. As alcohol consumption may negatively influence folate status and metabolism, we further tested whether the 
association between folate intake and breast cancer risk can be modified by alcohol assumption status. Three prospective studies and three case-control studies providing detailed results on dietary folate intake in relation to breast cancer risk along with stratification of alcohol consumption (Zhang et al, 1999; Negri et al, 2000; Rohan et al, 2000; Levi et al, 2001; Larsson et al, 2008; Islam et al, 2013) were identified. Four of the six independent studies showed significant inverse association between folate intake and breast cancer risk for women who had consumed relatively higher amounts of alcohol, and the summary risk estimates also suggested that higher folate intake may reduce breast cancer risk for those with high alcohol intake, with a pooled OR of $0.60(95 \%$ $\left.\mathrm{CI}=0.45-0.82 ; \quad I^{2}=57 \%\right)$ under the random-effects model (Figure 7); however, no such association was found for those women with lower or never alcohol intake (pooled OR $=0.92 ; 95 \%$ $C I=0.79-1.07 ; I^{2}=63 \%$; Figure 7). Egger's test suggested that there was no publication bias in the meta-analysis analysis (higher alcohol intake, $P=0.663$; lower alcohol intake, $P=0.509$ ). These data suggested that alcohol intake may modulate the association between folate intake and breast cancer risk, and folate may have preventive effects against breast cancer, especially for those women with higher alcohol intake.

Serum folate level and breast cancer risk. We identified 12 studies (Supplementary Table 3) that evaluated the circulating folate level and breast cancer risk (Wu et al, 1999; Goodman et al, 2001; Zhang et al, 2003; Beilby et al, 2004; Han et al, 2004; Chou et al, 2006; Rossi et al, 2006; Chou et al, 2007; Lin et al, 2008; Ericson et al, 2009, 2010; Lin et al, 2010). Of these, the four studies (Zhang et al, 2003; Chou et al, 2006; Ericson et al, 2010; Lin et al, 2010) that had performed in the same populations as the other four studies (Han et al, 2004; Chou et al, 2007; Lin et al, 2008; Ericson et al, 2009) were excluded for the meta-analysis. For the eight studies that met the inclusion criteria, four were nested case-control studies (Wu et al, 1999; Zhang et al, 2003; Lin et al, 2008; Ericson et al, 2009) and three were case-control studies (Goodman et al, 2001; Beilby et al, 2004; Chou et al, 2006). The 7 studies recruited a total of 2467 cases and 2888 controls. Another prospective cohort study that included 569 participants and 19 outcome patients evaluated the association between blood folate level and breast cancer risk (Rossi et al, 2006). Of them, four reports were carried out in United States, two in Australia, one in Sweden and one in China. Only the population-based case-control study conducted by Beilby et al (2004) reported a significantly reduced breast cancer risk for those with the highest quantile of circulating folate level compared with those in the lowest quantile, whereas other studies found no such association. From the meta-analysis of the relevant studies, we found significant association between the circulating folate level and breast cancer risk from neither prospective studies (pooled $\mathrm{RR}=1.04 ; 95 \%$ $\mathrm{CI}=0.76-1.42 ; \quad I^{2}=58 \%$ ) nor case-control studies (pooled $\mathrm{OR}=0.59 ; 95 \% \mathrm{CI}=0.26-1.31 ; I^{2}=78 \%$ ) under the random-effects model. Statistically significant heterogeneity among studies was found for both meta-analysis analyses, whereas no significant publication bias was found $(P=0.837$ for prospective studies and $P=0.118$ for case-control studies).

\section{DISCUSSION}

Two previous meta-analyses have evaluated folate intake, circulating folate level and breast cancer risk (Lewis et al, 2006; Larsson et al, 2007), based on 9 prospective studies and 14 case-control studies. Both studies found no clear evidence for significant association between folate intake or blood folate levels and breast cancer risk; however, they detected disagreements for the results from prospective studies and case-control studies. Both studies found that the pooled estimates of the case-control studies suggested a statistically significant association between dietary folate intake and breast cancer risk, but not for the prospective studies; however, the dose-response effects for folate on breast cancer risk were not extensively evaluated because of limited data (Lewis et al, 2006; Larsson et al, 2007). For the current metaanalysis, we included 16 prospective studies and 26 case-control studies that examined the association of folate with breast cancer risk. Our results suggested that higher dietary or total folate intake may not be associated with decreased breast cancer risk under the linearity relationship model for the prospective studies but have a significant negative correlation between breast cancer risk and dietary folate intake for the case-control studies, consistent with the two previous meta-analysis studies. Interestingly, with the generalised least squares regression model, we found that the dose effect of dietary folate level and breast cancer risk was departure from the linearity, and a U-shaped relationship was noticed between the dietary folate intake level and breast cancer risk for the

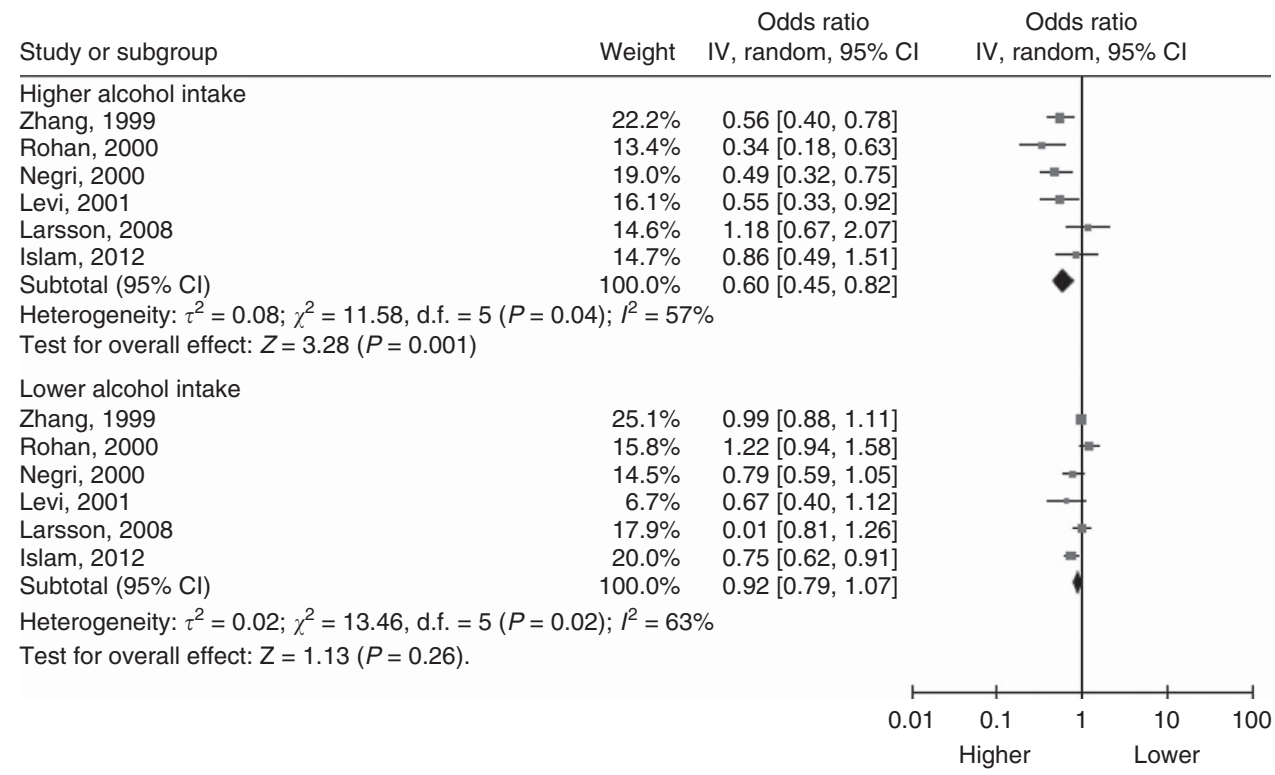

Figure 7. Association between dietary folate intake and breast cancer risk may be modified by alcohol consumption status of the women. 
prospective cohort studies. A significantly reduced breast cancer risk was found for women with daily dietary folate intake between 153 and $400 \mu \mathrm{g}$ compared with those $<153 \mu \mathrm{g}$ for the prospective studies, whereas women with daily dietary folate intake exceeding $400 \mu \mathrm{g}$ did not show a significant reduction in breast cancer risk. No evidence was noticed for the association between total folate intake and breast cancer risk for the prospective studies. The pooled estimate for the case-control studies suggested a significant negative correlation between daily dietary folate intake and breast cancer risk, and a $100 \mu \mathrm{g}$ per day increment of dietary folate confers an $\sim 9 \%$ reduction in breast cancer risk compared with those $<130.5 \mu \mathrm{g}$ per day. In addition, we found that a higher folate intake may reduce the breast cancer risk for women with higher alcohol consumption but not for those with lower alcohol consumption. These data suggested a potential preventive effect of folate against breast cancer risk; however, more epidemiological studies especially the intervention studies are warranted to further address the questions.

When the breast cancer risk estimates for the highest $v s$ the lowest category of the dietary folate intake or the estimates that reflected the $100 \mu \mathrm{g}$ per day standardised increment of dietary folate for the prospective studies were applied to calculate the summary association estimate, we found a null association between dietary folate intake and breast cancer risk. However, the generalised least squares regression model suggested a U-shaped relationship between folate intake and breast cancer risk, consistent with previous hypothesised statements (Ulrich, 2007). We found that the linearity dose-effect model is prone to underestimate the preventive effects for folate against breast cancer compared with the nonlinearity model (Figure 5). The U-shaped relationship between folate intake level and breast cancer risk also suggested that the preventive effects of folate against breast cancer is usually underestimated through comparing the highest $v s$ the lowest category of dietary folate intake level. It has been suggested that folate may play a dual role in cancer development: increasing folate may prevent tumour development before the existence of preneoplastic lesions, whereas folate supplementation may promote tumour progression if the preneoplastic lesions are present (Ulrich, 2007). Animal experiments also suggested that modest folate supplementation could reduce colorectal carcinogenesis, whereas excessive folate supplementation could lead to an enhanced tumour growth (Kim, 2004; Ulrich, 2007). Folic acid could enhance the DNA methylation-mediated transcriptional silencing of APC, PTEN and RAR $\beta 2$ tumour-suppressor genes in breast cancer that may lead to increased breast cancer risk (Lubecka-Pietruszewska et al, 2013). These studies indicated that excessive folate intake may not only accelerate DNA synthesis but also influence the one-carbon metabolism homeostasis that may lead to breast cancer development. For the case-control studies, although the primary pooled results from the case-control studies suggested that women in the highest category of folate intake showed a statistically significant decreased breast cancer risk, there were significant publication bias existing as suggested by Egger's test. When the trim and fill method was applied for the adjustment for the publication bias, no significant association between folate intake and breast cancer risk under the assumption of linearity relationship for fotale intake and breast cancer risk was noticed. In the stratification studies, we found that highest category of folate intake confers a prominent reduced breast cancer risk for postmenopausal women, studies with higher quality, studies with a hospital case-control design or without adjustment for alcohol (Table 2). We also found that the higher folate intake showed significant preventative effects for breast cancer for populations out of the United States, but not for the US populations. Generalised folic acid fortification of flour and cereal grain products at a level of $140 \mu \mathrm{g}$ per $100 \mathrm{~g}$ has been mandated in the United States and Canada since 1996. Thus, the protective effects from folate intake may be weaker in these populations with a relatively higher folate intake level. Whether higher folate would reduce breast cancer risk in the populations without folate fortification or lower folate intake level still need further investigations. With the generalised least squares regression model, we also found a significant negative correlation between the breast cancer risk and folate intake level under the assumption of both linearity and nonlinearity dose-effect models, although no U-shaped relationship between dietary folate intake level and breast cancer risk was noticed. These results suggested that the doses and intervention time are critical for preventive effects of folate against breast cancer.

Some studies suggested that for subjects with moderate or high level of alcohol intake, higher folate intake may lead to a reduced risk of breast cancer. It is known that alcohol could influence the absorption and metabolism of folate (Halsted et al, 2002), and the discrepant results for the preventive effects for folate intake between high and low alcohol consumption group could probably be attributed to the impairment of folate absorption and metabolism by alcohol that render individuals with high alcohol intake to be more susceptible to the protective effect of folate intake, despite that moderate alcohol intake may not influence serum folate concentrations (Laufer et al, 2004). Nevertheless, it should be noted that participants with relative higher alcohol intake appeared to be less conscious about health and are likely to have relatively lower folate intake that may lead to the lower basal level of folate than those consuming low or no alcohol (Stolzenberg-Solomon et al, 2006). On the other hand, folate intake may also modify alcohol-induced breast cancer susceptibility. Alcohol consumption, resulting in elevated oestrogen and androgen concentrations, was reported to increase breast cancer risk; and folate intake may attenuate such effect (Baglietto et al, 2005; Stolzenberg-Solomon et al, 2006; Duffy et al, 2009; Kawai et al, 2011). The interactive effect between folate and alcohol intake on breast cancer risk still needs to be evaluated in future studies.

Consistent results were found for the prospective and the casecontrol studies regarding the preventive effects of folate on breast cancer risk; however, the results should be interpreted carefully as dietary folate mainly from leafy vegetables, legumes, egg yolk, baker's yeast and so on that also contain other nutrients may lead to reduced breast cancer risk, and the preventive effects of folate that were noticed here may be conferred by other factors. Secondly, the dose-effect relationship pattern for the dietary folate intake level and the breast cancer risk was different between the prospective and the case-control studies. A U-shaped relationship between folate intake level and breast cancer risk was identified in the prospective studies (Figure 5), whereas a consecutive trend of reduced breast cancer was found for women with high folate level for the case-control studies (Figure 6). Patients in the case-control studies usually overestimate their lack of folate intake when they are subconsciously informed that folate could be a favourable nutrient, and hence the case-control studies are more prone to suffer from recall bias and selection bias. The U-shaped relationship is hard to be identified in the case-control studies. However, the patterns for the association between folate intake and breast cancer risk need further investigations, and especially the most favourable folate intake doses should be elucidated. Thirdly, participants would probably change their living habits during the follow-up for the prospective studies, as most of the studies did not update dietary information during the follow-up studies. Misclassification of the long-term folate intake level may also have been introduced for many of the prospective studies, as the flour and cereal grain products in the United States have been fortified with folic acid since 1998. For those prospective studies covered pre- or post-fortification period, the studies may underestimate the dietary folate intake level as they usually assessed the baseline intake level. Fourthly, whether the food frequency questionnaires (FFQs) used in prospective and case-control studies could 
objectively reveal folate intake level from foods or supplements remains unknown. Farming techniques, climate, soil content, craftsmanship and others could be the possible influencing factors for folate contents in foods or supplements. Finally, differences in sample size, study region, study design and methods of assessment may cause heterogeneity among studies that may contribute to the differences in the stratification analysis, especially for the casecontrol studies. Thus, more well-designed epidemiological studies are warranted to further evaluate the preventive effects of folate against breast cancer risk.

In conclusion, our findings have revealed the potential nonlinearity dose effect for dietary folate level against breast cancer risk for the prospective and case-control studies, and modest folate intake may reduce the breast cancer risk. We also found that folate may reduce breast cancer risk for women with high alcohol intake but not for those with lower alcohol intake. Considering the complexity of pathways of folate metabolism and utilisations, the dose and timing of folate intake should be taken into consideration, and more prospective studies and intervention studies are necessary for further evaluation of the effects of folic acid fortification according to specific dietary habits or genetic background of different populations.

\section{ACKNOWLEDGEMENTS}

We thank Qingyi Wei, from the Department of Epidemiology, Division of Cancer Prevention and Population Sciences, The University of Texas MD Anderson Cancer Center, Houston, TX, USA, and Wei Zhang from the Institute for Food Safety and Health, Illinois Institute of Technology, Bedford Park, IL, USA, for their help in manuscript editing and preparation. This study was supported by grants from the Ministry of Science and Technology of China (2012BAK01B00), the National Nature Science Foundation (81125020, 81302507 and 81302809), the Science and Technology Commission of Shanghai Municipality (12XD1407000, 12431900500, 11391902000 and 12391901300), Director Foundation (20090101) and the Food Safety Research Center and Key Laboratory of Food Safety Research of INS, SIBS, CAS. Peizhan Chen was partially supported by the SA-SIBS scholarship program.

\section{CONFLICT OF INTEREST}

The authors declare no conflict of interest.

\section{REFERENCES}

Adzersen KH, Jess P, Freivogel KW, Gerhard I, Bastert G (2003) Raw and cooked vegetables, fruits, selected micronutrients, and breast cancer risk: a case-control study in Germany. Nutr Cancer 46: 131-137.

Baglietto L, English DR, Gertig DM, Hopper JL, Giles GG (2005) Does dietary folate intake modify effect of alcohol consumption on breast cancer risk? Prospective cohort study. BMJ 331: 807.

Bassett JK, Baglietto L, Hodge AM, Severi G, Hopper JL, English DR, Giles GG (2013) Dietary intake of B vitamins and methionine and breast cancer risk. Cancer Causes Control 24: 1555-1563.

Beasley JM, Coronado GD, Livaudais J, Angeles-Llerenas A, Ortega-Olvera C, Romieu I, Lazcano-Ponce E, Torres-Mejia G (2010) Alcohol and risk of breast cancer in Mexican women. Cancer Causes Control 21: 863-870.

Beilby J, Ingram D, Hahnel R, Rossi E (2004) Reduced breast cancer risk with increasing serum folate in a case-control study of the C677T genotype of the methylenetetrahydrofolate reductase gene. Eur J Cancer 40: $1250-1254$.

Chen J, Gammon MD, Chan W, Palomeque C, Wetmur JG, Kabat GC, Teitelbaum SL, Britton JA, Terry MB, Neugut AI, Santella RM (2005)
One-carbon metabolism, MTHFR polymorphisms, and risk of breast cancer. Cancer Res 65: 1606-1614.

Chen P, Hu P, Xie D, Qin Y, Wang F, Wang H (2010) Meta-analysis of vitamin D, calcium and the prevention of breast cancer. Breast Cancer Res Treat 121: 469-477.

Cho E, Holmes M, Hankinson SE, Willett WC (2007) Nutrients involved in one-carbon metabolism and risk of breast cancer among premenopausal women. Cancer Epidemiol Biomarkers Prev 16: 2787-2790.

Cho E, Spiegelman D, Hunter DJ, Chen WY, Zhang SM, Colditz GA, Willett WC (2003) Premenopausal intakes of vitamins A, C, and E, folate, and carotenoids, and risk of breast cancer. Cancer Epidemiol Biomarkers Prev 12: 713-720.

Choi SW, Mason JB (2000) Folate and carcinogenesis: an integrated scheme. J Nutr 130: 129-132.

Chou YC, Lee MS, Wu MH, Shih HL, Yang T, Yu CP, Yu JC, Sun CA (2007) Plasma homocysteine as a metabolic risk factor for breast cancer: findings from a case-control study in Taiwan. Breast Cancer Res Treat 101: 199-205.

Chou YC, Wu MH, Yu JC, Lee MS, Yang T, Shih HL, Wu TY, Sun CA (2006) Genetic polymorphisms of the methylenetetrahydrofolate reductase gene, plasma folate levels and breast cancer susceptibility: a case-control study in Taiwan. Carcinogenesis 27: 2295-2300.

Dong JY, Qin LQ (2011) Soy isoflavones consumption and risk of breast cancer incidence or recurrence: a meta-analysis of prospective studies. Breast Cancer Res Treat 125: 315-323.

Duffy CM, Assaf A, Cyr M, Burkholder G, Coccio E, Rohan T, McTiernan A, Paskett E, Lane D, Chetty VK (2009) Alcohol and folate intake and breast cancer risk in the WHI Observational Study. Breast Cancer Res Treat 116 : 551-562.

Duval S, Tweedie R (2000) Trim and fill: a simple funnel-plot-based method of testing and adjusting for publication bias in meta-analysis. Biometrics 56: $455-463$.

Ericson U, Borgquist S, Ivarsson MI, Sonestedt E, Gullberg B, Carlson J, Olsson H, Jirstrom K, Wirfalt E (2010) Plasma folate concentrations are positively associated with risk of estrogen receptor beta negative breast cancer in a Swedish nested case control study. J Nutr 140: 1661-1668.

Ericson U, Sonestedt E, Gullberg B, Olsson H, Wirfalt E (2007) High folate intake is associated with lower breast cancer incidence in postmenopausal women in the Malmo Diet and Cancer cohort. Am J Clin Nutr 86: 434-443.

Ericson UC, Ivarsson MI, Sonestedt E, Gullberg B, Carlson J, Olsson H, Wirfalt E (2009) Increased breast cancer risk at high plasma folate concentrations among women with the MTHFR 677T allele. Am J Clin Nutr 90: 1380-1389.

Feigelson HS, Jonas CR, Robertson AS, McCullough ML, Thun MJ, Calle EE (2003) Alcohol, folate, methionine, and risk of incident breast cancer in the American Cancer Society Cancer Prevention Study II Nutrition Cohort. Cancer Epidemiol Biomarkers Prev 12: 161-164.

Franceschi S (1997) Micronutrients and breast cancer. Eur J Cancer Prev 6: 535-539.

Freudenheim JL, Marshall JR, Vena JE, Laughlin R, Brasure JR, Swanson MK, Nemoto T, Graham S (1996) Premenopausal breast cancer risk and intake of vegetables, fruits, and related nutrients. J Natl Cancer Inst 88: 340-348.

Gao CM, Tang JH, Cao HX, Ding JH, Wu JZ, Wang J, Liu YT, Li SP, Su P, Matsuo K, Takezaki T, Tajima K (2009) MTHFR polymorphisms, dietary folate intake and breast cancer risk in Chinese women. J Hum Genet 54: 414-418.

Gong Z, Ambrosone CB, McCann SE, Zirpoli G, Chandran U, Hong CC, Bovbjerg DH, Jandorf L, Ciupak G, Pawlish K, Lu Q, Hwang H, Khoury T, Wiam B, Bandera EV (2014) Associations of dietary folate, vitamin B6, B12 and methionine intake with risk of breast cancer among African American (AA) and European American (EA) women. Int J Cancer 134: 1422-1435.

Goodman JE, Lavigne JA, Wu K, Helzlsouer KJ, Strickland PT, Selhub J, Yager JD (2001) COMT genotype, micronutrients in the folate metabolic pathway and breast cancer risk. Carcinogenesis 22: 1661-1665.

Graham S, Hellmann R, Marshall J, Freudenheim J, Vena J, Swanson M, Zielezny M, Nemoto T, Stubbe N, Raimondo T (1991) Nutritional epidemiology of postmenopausal breast cancer in western New York. Am J Epidemiol 134: 552-566.

Greenland S, Longnecker MP (1992) Methods for trend estimation from summarized dose-response data, with applications to meta-analysis. Am J Epidemiol 135: 1301-1309. 
Halsted CH, Villanueva JA, Devlin AM, Chandler CJ (2002) Metabolic interactions of alcohol and folate. J Nutr 132: 2367S-2372S.

Han J, Hankinson SE, Zhang SM, De Vivo I, Hunter DJ (2004) Interaction between genetic variations in DNA repair genes and plasma folate on breast cancer risk. Cancer Epidemiol Biomarkers Prev 13: 520-524.

Hankinson SE, Colditz GA, Willett WC (2004) Towards an integrated model for breast cancer etiology: the lifelong interplay of genes, lifestyle, and hormones. Breast Cancer Res 6: 213-218.

Islam T, Ito H, Sueta A, Hosono S, Hirose K, Watanabe M, Iwata H, Tajima K, Tanaka H, Matsuo K (2013) Alcohol and dietary folate intake and the risk of breast cancer: a case-control study in Japan. Eur J Cancer Prev 22: 358-366.

Kabat GC, Miller AB, Jain M, Rohan TE (2008) Dietary intake of selected B vitamins in relation to risk of major cancers in women. Br J Cancer 99: 816-821.

Kawai M, Minami Y, Kakizaki M, Kakugawa Y, Nishino Y, Fukao A, Tsuji I, Ohuchi N (2011) Alcohol consumption and breast cancer risk in Japanese women: the Miyagi Cohort study. Breast Cancer Res Treat 128: 817-825.

Khan N, Afaq F, Mukhtar H (2008) Cancer chemoprevention through dietary antioxidants: progress and promise. Antioxid Redox Signal 10: 475-510.

Kim YI (2004) Folate, colorectal carcinogenesis, and DNA methylation: lessons from animal studies. Environ Mol Mutagen 44: 10-25.

Lajous M, Lazcano-Ponce E, Hernandez-Avila M, Willett W, Romieu I (2006a) Folate, vitamin $\mathrm{B}(6)$, and vitamin $\mathrm{B}(12)$ intake and the risk of breast cancer among Mexican women. Cancer Epidemiol Biomarkers Prev 15: 443-448.

Lajous M, Romieu I, Sabia S, Boutron-Ruault MC, Clavel-Chapelon F (2006b) Folate, vitamin B12 and postmenopausal breast cancer in a prospective study of French women. Cancer Causes Control 17: 1209-1213.

Larsson SC, Bergkvist L, Wolk A (2008) Folate intake and risk of breast cancer by estrogen and progesterone receptor status in a Swedish cohort. Cancer Epidemiol Biomarkers Prev 17: 3444-3449.

Larsson SC, Giovannucci E, Wolk A (2007) Folate and risk of breast cancer: a meta-analysis. J Natl Cancer Inst 99: 64-76.

Laufer EM, Hartman TJ, Baer DJ, Gunter EW, Dorgan JF, Campbell WS, Clevidence BA, Brown ED, Albanes D, Judd JT, Taylor PR (2004) Effects of moderate alcohol consumption on folate and vitamin $\mathrm{B}(12)$ status in postmenopausal women. Eur J Clin Nutr 58: 1518-1524.

Le Marchand L, Haiman CA, Wilkens LR, Kolonel LN, Henderson BE (2004) MTHFR polymorphisms, diet, HRT, and breast cancer risk: the multiethnic cohort study. Cancer Epidemiol Biomarkers Prev 13: 2071-2077.

Lee SA, Lee KM, Lee SJ, Yoo KY, Park SK, Noh DY, Ahn SH, Kang D (2010) Antioxidant vitamins intake, ataxia telangiectasia mutated (ATM) genetic polymorphisms, and breast cancer risk. Nutr Cancer 62: 1087-1094.

Lee SA, Lee KM, Yoo KY, Noh DY, Ahn SH, Kang D (2012) Combined effects of antioxidant vitamin and NOS3 genetic polymorphisms on breast cancer risk in women. Clin Nutr 31: 93-98.

Levi F, Pasche C, Lucchini F, La Vecchia C (2001) Dietary intake of selected micronutrients and breast-cancer risk. Int J Cancer 91: 260-263.

Lewis SJ, Harbord RM, Harris R, Smith GD (2006) Meta-analyses of observational and genetic association studies of folate intakes or levels and breast cancer risk. J Natl Cancer Inst 98: 1607-1622.

Lin J, Lee IM, Cook NR, Selhub J, Manson JE, Buring JE, Zhang SM (2008) Plasma folate, vitamin B-6, vitamin B-12, and risk of breast cancer in women. Am J Clin Nutr 87: 734-743.

Lin J, Lee IM, Song Y, Cook NR, Selhub J, Manson JE, Buring JE, Zhang SM (2010) Plasma homocysteine and cysteine and risk of breast cancer in women. Cancer Res 70: 2397-2405.

Lubecka-Pietruszewska K, Kaufman-Szymczyk A, Stefanska B, Fabianowska-Majewska K (2013) Folic acid enforces DNA methylationmediated transcriptional silencing of PTEN, APC and RARbeta2 tumour suppressor genes in breast cancer. Biochem Biophys Res Commun 430: 623-628.

Ma E, Iwasaki M, Junko I, Hamada GS, Nishimoto IN, Carvalho SM, Motola JJ, Laginha FM, Tsugane S (2009a) Dietary intake of folate, vitamin B6, and vitamin B12, genetic polymorphism of related enzymes, and risk of breast cancer: a case-control study in Brazilian women. BMC Cancer 9: 122.

Ma E, Iwasaki M, Kobayashi M, Kasuga Y, Yokoyama S, Onuma H, Nishimura H, Kusama R, Tsugane S (2009b) Dietary intake of folate, vitamin B2, vitamin B6, vitamin B12, genetic polymorphism of related enzymes, and risk of breast cancer: a case-control study in Japan. Nutr Cancer 61: 447-456.
Marian C, Tao M, Mason JB, Goerlitz DS, Nie J, Chanson A, Freudenheim JL, Shields PG (2011) Single nucleotide polymorphisms in uracil-processing genes, intake of one-carbon nutrients and breast cancer risk. Eur J Clin Nutr 65: 683-689.

Maruti SS, Ulrich CM, Jupe ER, White E (2009a) MTHFR C677T and postmenopausal breast cancer risk by intakes of one-carbon metabolism nutrients: a nested case-control study. Breast Cancer Res 11: R91.

Maruti SS, Ulrich CM, White E (2009b) Folate and one-carbon metabolism nutrients from supplements and diet in relation to breast cancer risk. Am J Clin Nutr 89: 624-633.

Negri E, La Vecchia C, Franceschi S (2000) Re: dietary folate consumption and breast cancer risk. J Natl Cancer Inst 92: 1270-1271.

Orsini N, Bellocco R, Greenland S (2006) Generalized least squares for trend estimation of summarized dose-response data. Stata J 6: 40-57.

Potischman N, Swanson CA, Coates RJ, Gammon MD, Brogan DR, Curtin J, Brinton LA (1999) Intake of food groups and associated micronutrients in relation to risk of early-stage breast cancer. Int J Cancer 82: 315-321.

Rohan TE, Jain MG, Howe GR, Miller AB (2000) Dietary folate consumption and breast cancer risk. J Natl Cancer Inst 92: 266-269.

Ronco A, De Stefani E, Boffetta P, Deneo-Pellegrini H, Mendilaharsu M, Leborgne F (1999) Vegetables, fruits, and related nutrients and risk of breast cancer: a case-control study in Uruguay. Nutr Cancer 35: 111-119.

Rossi E, Hung J, Beilby JP, Knuiman MW, Divitini ML, Bartholomew H (2006) Folate levels and cancer morbidity and mortality: prospective cohort study from Busselton, Western Australia. Ann Epidemiol 16: 206-212.

Roswall N, Olsen A, Christensen J, Dragsted LO, Overvad K, Tjonneland A (2010) Micronutrient intake and breast cancer characteristics among postmenopausal women. Eur J Cancer Prev 19: 360-365.

Sellers TA, Grabrick DM, Vierkant RA, Harnack L, Olson JE, Vachon CM, Cerhan JR (2004) Does folate intake decrease risk of postmenopausal breast cancer among women with a family history? Cancer Causes Control 15: 113-120.

Sellers TA, Kushi LH, Cerhan JR, Vierkant RA, Gapstur SM, Vachon CM, Olson JE, Therneau TM, Folsom AR (2001) Dietary folate intake, alcohol, and risk of breast cancer in a prospective study of postmenopausal women. Epidemiology 12: 420-428.

Sellers TA, Vierkant RA, Cerhan JR, Gapstur SM, Vachon CM, Olson JE, Pankratz VS, Kushi LH, Folsom AR (2002) Interaction of dietary folate intake, alcohol, and risk of hormone receptor-defined breast cancer in a prospective study of postmenopausal women. Cancer Epidemiol Biomarkers Prev 11: 1104-1107.

Sharp L, Little J, Schofield AC, Pavlidou E, Cotton SC, Miedzybrodzka Z, Baird JO, Haites NE, Heys SD, Grubb DA (2002) Folate and breast cancer: the role of polymorphisms in methylenetetrahydrofolate reductase (MTHFR). Cancer Lett 181: 65-71.

Shrubsole MJ, Gao YT, Cai Q, Shu XO, Dai Q, Hebert JR, Jin F, Zheng W (2004) MTHFR polymorphisms, dietary folate intake, and breast cancer risk: results from the Shanghai Breast Cancer Study. Cancer Epidemiol Biomarkers Prev 13: 190-196.

Shrubsole MJ, Jin F, Dai Q, Shu XO, Potter JD, Hebert JR, Gao YT, Zheng W (2001) Dietary folate intake and breast cancer risk: results from the Shanghai Breast Cancer Study. Cancer Res 61: 7136-7141.

Shrubsole MJ, Shu XO, Li HL, Cai H, Yang G, Gao YT, Gao J, Zheng W (2011) Dietary B vitamin and methionine intakes and breast cancer risk among Chinese women. Am J Epidemiol 173: 1171-1182.

Stevens VL, McCullough ML, Sun J, Gapstur SM (2010) Folate and other one-carbon metabolism-related nutrients and risk of postmenopausal breast cancer in the Cancer Prevention Study II Nutrition Cohort. Am J Clin Nutr 91: 1708-1715.

Stolzenberg-Solomon RZ, Chang SC, Leitzmann MF, Johnson KA, Johnson C, Buys SS, Hoover RN, Ziegler RG (2006) Folate intake, alcohol use, and postmenopausal breast cancer risk in the Prostate, Lung, Colorectal, and Ovarian Cancer Screening Trial. Am J Clin Nutr 83: 895-904.

Suzuki T, Matsuo K, Hirose K, Hiraki A, Kawase T, Watanabe M, Yamashita T, Iwata H, Tajima K (2008) One-carbon metabolism-related gene polymorphisms and risk of breast cancer. Carcinogenesis 29: 356-362.

Tavani A, Malerba S, Pelucchi C, Dal Maso L, Zucchetto A, Serraino D, Levi F, Montella M, Franceschi S, Zambon A, La Vecchia C (2012) Dietary folates and cancer risk in a network of case-control studies. Ann Oncol 23: 2737-2742.

Thorand B, Kohlmeier L, Simonsen N, Croghan C, Thamm M (1998) Intake of fruits, vegetables, folic acid and related nutrients and risk of breast cancer in postmenopausal women. Public Health Nutr 1: 147-156. 
Tjonneland A, Christensen J, Olsen A, Stripp C, Nissen SB, Overvad K, Thomsen BL (2006) Folate intake, alcohol and risk of breast cancer among postmenopausal women in Denmark. Eur J Clin Nutr 60: 280-286.

Ulrich CM (2007) Folate and cancer prevention: a closer look at a complex picture. Am J Clin Nutr 86: 271-273.

Wu K, Helzlsouer KJ, Comstock GW, Hoffman SC, Nadeau MR, Selhub J (1999) A prospective study on folate, B12, and pyridoxal $5^{\prime}$-phosphate (B6) and breast cancer. Cancer Epidemiol Biomarkers Prev 8: 209-217.

Yang D, Baumgartner RN, Slattery ML, Wang C, Giuliano AR, Murtaugh MA, Risendal BC, Byers T, Baumgartner KB (2013) Dietary intake of folate, $\mathrm{B}$-vitamins and methionine and breast cancer risk among Hispanic and non-Hispanic white women. PLoS One 8: e54495.

Yang YJ, Hwang SH, Kim HJ, Nam SJ, Kong G, Kim MK (2010) Dietary intake of nitrate relative to antioxidant vitamin in relation to breast cancer risk: a case-control study. Nutr Cancer 62: 555-566.

Zhang CX, Ho SC, Chen YM, Lin FY, Fu JH, Cheng SZ (2011) Dietary folate, vitamin $\mathrm{B} 6$, vitamin $\mathrm{B} 12$ and methionine intake and the risk of breast cancer by oestrogen and progesterone receptor status. Br J Nutr 106: 936-943.

Supplementary Information accompanies this paper on British Journal of Cancer website (http://www.nature.com/bjc)
Zhang S, Hunter DJ, Hankinson SE, Giovannucci EL, Rosner BA, Colditz GA, Speizer FE, Willett WC (1999) A prospective study of folate intake and the risk of breast cancer. JAMA 281: 1632-1637.

Zhang SM, Hankinson SE, Hunter DJ, Giovannucci EL, Colditz GA, Willett WC (2005) Folate intake and risk of breast cancer characterized by hormone receptor status. Cancer Epidemiol Biomarkers Prev 14: 2004-2008.

Zhang SM, Willett WC, Selhub J, Hunter DJ, Giovannucci EL, Holmes MD, Colditz GA, Hankinson SE (2003) Plasma folate, vitamin B6, vitamin B12, homocysteine, and risk of breast cancer. J Natl Cancer Inst 95: 373-380.

Zhu K, Davidson NE, Hunter S, Yang X, Payne-Wilks K, Roland CL, Phillips D, Bentley C, Dai M, Williams SM (2003) Methyl-group dietary intake and risk of breast cancer among African-American women: a case-control study by methylation status of the estrogen receptor alpha genes. Cancer Causes Control 14: 827-836.

This work is published under the standard license to publish agreement. After 12 months the work will become freely available and the license terms will switch to a Creative Commons AttributionNonCommercial-Share Alike 3.0 Unported License. 